\title{
IS IT POSSIBLE TO OVERCOME DISGUST? AN AMBIVALENT EMOTION
}

\begin{abstract}
A growing interest for the emotion of disgust has recently arisen in international contexts across several fields of research, ranging from empirical psychology and psychoanalysis, to anthropology, art criticism and sociology. While tackling the most basic issues connected to disgust, this article aims, primarily, to unveil some previously neglected aspects within historical theories of disgust, and to present a theory of disgust that is able to provide a suitable answer to some open questions in the contemporary debate in philosophy, such as the role of the body in ethical issues.
\end{abstract}

\section{The debate on disgust}

In the contemporary debate, it is currently possible to isolate a few positions on the topic of disgust.

The historical approach presented by Mennighaus in Disgust: the Theory and History of a Strong Sensation (Menninghaus 2003) is an indispensable point of reference for studies on disgust. My approach to reading disgust in the light of the notion of taboo is undoubtedly indebted to Menninghaus. My idea of disgust, however, differs from Menninghaus's work in important respects. Whereas Menninghaus's investigation is presented from a methodological point of view as a reconstruction of the philosophical history of disgust, beginning in the eighteenth century and ending with Julia Kristeva's theory of abjection, my inquiry is not historical in nature but seeks to provide a theoretical account (Kristeva 1982). Moreover, for obvious chronological reasons, it does not discuss Martha Nussbaum's controversial condemnation of disgust. It is therefore worthwhile to continue Menninghaus's work by developing a theory that directly engages with Nussbaum's contribution.

Martha Nussbaum follows an ethical-political approach to disgust in: Hiding from Humanity: Disgust, Shame and the Law (Nussbaum 2003) and in From Disgust to Humanity: Sexual Orientation and Constitutional Law (Nussbaum 2010). Nussbaum pre- 
sents one of the most discussed theories of disgust and her perspective is clear: in line with moral emotivism, disgust is an emotion which is not compatible with society and on the exclusion of which it is possible to build a politics of inclusiveness. Nussbaum discusses the very core of disgust, even showing the danger of promoting it.

In this way, traditional theories of disgust are once more put in question and an original point of view emerges.

The definition of disgust is thus subjected to a more general agenda and some important aspects are neglected, such as the ambivalence of disgust or the impossibility of actually overcoming it. Although Nussbaum calls for an overcoming of disgust and does not believe it can be oriented toward inclusive practices, she does concede that education through art can be a good practice for managing disgust in the impossibility of its complete overcoming.

The main reference for an aesthetic approach is presented by C. Korsmeyer in Savoring Disgust: The Foul and the Fair in Aesthetics (Korsmeyer 2011). Korsmeyer's study analyzes the emotion of disgust in detail and considers the aesthetic forms it can assume in works of art and in foods. The emotion of disgust is described as a mode of cognition and as an intimate apprehension of physical mortality. After a survey of examples of disgust in contemporary art, the book supports the idea that disgust can border on the beautiful in aesthetic experience and appear attractive.

Its detailed analysis strongly supports the idea of the ambivalence of disgust, especially in aesthetic experience. It provides an articulated and well-argued definition of disgust through examples. Korsmeyer's text remains however limited to a consideration of the disgusting in certain artistic phenomena but does not confront the issues raised by Nussbaum. Moreover, while she considers the attraction that can lurk in aesthetic disgust, she does not provide a reason for it and does not consider ambivalence as an essential feature of this complex emotion.

The ambivalence of disgust is instead the focus of the psychoanalytical approach. Although Freud never wrote directly about disgust, the emotion of disgust is often present in his works, which provide a very useful conceptual framework for understanding its nature. Freud in particular allows us to grasp the peculiar ambivalence of disgust by highlighting the perverse attraction to the disgusting that hides in total rejection. In particular, the 1930 text Civilisation and Its Discontents allows us to read disgust 
as a trait of the civilisation process and to link it to the notion of taboo (Freud 1999, 1930, 99-100). Psychoanalysis provides a remarkable conceptual apparatus for interpreting disgust in its complexity, without reducing it to a mere cataloguing of phenomena. Thanks to the ambivalence of disgust highlighted by Freud, it is possible, for example, to consider its dual nature between nature and culture, repulsion and attraction, body and soul, representability and unrepresentability (Freud 1999, 1930,144).

In the same year (1929) in which it was written Freud's Civilisation and Its Discontents, A. Kolnai, in On Disgust, presented a phenomenological approach to disgust (Kolnai 2003, 1929). This is the first philosophical book entirely dedicated to disgust. Kolnai was a student of Husserl and applied the method of phenomenology to disgust, providing an accurate description of it. The text focuses entirely on disgust and highlights some essential aspects in a theoretically perspicuous way, notably concerning its moral nature, the impossibility of overcoming it, its ambivalence and its relationship with anxiety and fear. Kolnai also provides an extensive and orderly survey of phenomena pertaining to the realm of disgust.

Psychoanalysis has then influenced various discussions of disgust in different field. For example, starting with Mary Douglas' text, Purity and Danger (Douglas 1966), the sociological implications of disgust as a demarcation factor in a society have been thoroughly investigated. Through fear of contagion and exclusionary practices, disgust would be an emotional element that indicates what cannot be assimilated by a society, drawing a clear boundary between us and the other. More recent studies, such as that of William Ian Miller (Miller 1997), continue in this direction. For our present day, these studies are extremely useful and allow us to consider both the cultural relativity of disgust and its constant and transversal presence in all societies. In addition, through analyses in the field, these studies allow disgust to be defined as an important sociological demarcation factor.

A Freudian approach to disgust has recently been proposed also by Jean Clair in De Immundo (Clair 2004). Through an analysis of some contemporary works of art, Clair proposes a complex analysis of the presence of disgust in art and questions its meaning. While focusing on the question of the body and its representation in art, a reading such as Jean Clair's takes into account above all the danger of these artistic phenomena and runs the risk of 
providing a conservative reading. In other words, it does not consider the possibility of an ethical function of the representation of disgust in art.

However, in recent years, an investigation of disgust in the field of empirical psychology (i.e. an explanation of psychological phenomena based on empirical observations and the experimental method) has prevailed. Above all, the research group led by Paul Rozin has provided an extensive description of the emotion of disgust, rendering it in all its empirical declinations (Rozin 2008). The most recent studies conducted by Winfried Menninghaus at the Max Planck Institut für empirische Ästhetik also point in this direction (Menninghaus, W., Wagner, V., Wassiliwizky, E., et al., 2019).

Empirical analyses allow a precise description of the phenomenon and provide for the emotion a series of classification criteria that make it possible to frame disgust in the current study of emotional states through scientific data. Empirical psychology also provides results that allow the measurement of different degrees of disgust according to various typologies.

\section{Defining disgust}

A general definition of disgust is preliminarily to be assumed: by disgust I understand a total rejection that generates a motion of repulsion and removal of an object that is in the proximity of the subject, without constituting a real danger.

Based on this definition, I would like to combine the aesthetic approach and the psychoanalytic approach mentioned above. In reference to the notion of taboo, I assume the ambivalence of disgust and I consider the emotion of disgust, essentially natural and cultural at the same time, as a typical trait of the process of human civilization that distinguishes humans from animals (Freud 1929), at variance with Martha Nussbaum's interpretation which instead sees in disgust a typical trait of the persistent animality in human beings and that therefore must be overcome (Nussbaum 2010, 26).

The definition of disgust that I assume here, in accordance with the psychoanalytic approach, can be compared with the aesthetic experience of the work of art. The indulging of disgust in artistic creation would only confirm the fact that only that which is domesticated, i.e. that which does not arouse genuine disgust, can be assimilated by art. Genuine disgust, on the other hand, re- 
mains taboo insofar as it indicates the absolutely other, the unassimilable, a non-domesticated animality alien to the process of civilisation. This is, moreover, what classical aesthetics has already shown, and which today can be re-read in Freudian terms. The categories of classical aesthetics make it possible to elaborate a philosophical response capable of reading the presence of the disgusting in art and of restoring this phenomenon in all its complexity. One could limit oneself to reading disgusting artistic phenomena as art's search for ever new and ever more violent stimuli. But this is only part of the answer that philosophy can give today. In the history of thought, and of aesthetics in particular, the category of disgust arose with the very emergence of the society of taste, in the Age of Enlightenment, but it cannot be defined in simply oppositional terms (see Feloj 2017, 22-30).

Taste and disgust are, in fact, profoundly interconnected, and the definition of one entails the definition of the other. Even from a theoretical point of view, regardless of its historical development, the notion of disgust paints a complex picture: disgust is in fact primarily a physiological reaction, but one that can also have a moral declination. It is an emotional response, only apparently connected to natural dynamics, and endowed with a profoundly cultural character.

The ambiguity within which disgust moves, between need and satiety, is not without problems. If one considers the German term used since the 18th century to indicate the category of disgust, Ekel, one discovers that disgust indicates both an absolute and irredeemable refusal and nausea due to excessive satiety. This lexical ambiguity is not insignificant for the evolution of the welldefined, and decisive, debate on disgust that took place in Germany from the 1750s onwards (Feloj 2017, 48-53). The question that drives this debate is whether art is legitimised to represent disgust. The discussion of this issue will lead to a definition of beauty, of the work of art and, finally, of aesthetics and its limits.

What makes disgust the taboo par excellence in artistic representation can be traced back to two characteristics. For Mendelssohn, disgust was already essentially linked to the "darkest of all senses", smell, touch and taste (Mendelssohn, 1972, 1771, JubA, V.1, 131). The sensation of disgust cannot therefore dwell, except by association, in an experience, such as artistic experience, which is primarily visual and auditory; or, to put it otherwise, which is the highest product of the civilisation process and, 
only mediately, i.e. through a primarily intellectual enjoyment, can recall the state of animality above which it has elevated us. The second essential characteristic of disgust, again starting with the 18th-century debate, has to do with the distinction between nature and art. For the authors of classical German aesthetics, the work of art is first and foremost a form of illusion. For Lessing, the poet must make us 'believe' that we are immediately 'seeing' Helen or Achilles' shield; artistic representation must achieve a complex balance between apparent naturalness and illusory construction (Lessing, 1990, 1766).

Aesthetic illusion is possible because art acts as a medium that allows a privileged and framed view of reality. Disgust, on the other hand, is a reaction without mediation. It is an immediate refusal that admits no redemption, and is triggered by a real and truly repugnant object. If, therefore, art confuses the planes of reality and illusion, disgust is a violent reaction that upsets this balance. Thus if art were to generate a reaction of genuine disgust, it would cease to be illusion and become reality; and with that, it would no longer be art. In the light of ambiguous trait of disgust, this category can be defined as the taboo of art.

\section{Culture and body}

Beyond the legitimation of disgust in art, disgust indicates something unassimilable, something absolutely other that remains inaccessible to art. As a totally negative reaction, disgust assumes a discriminatory function and a defensive barrier raised by the process of civilisation. The idea of disgust as a taboo of art has found an interesting echo in contemporary times through the notion of "abject", which, especially since the 1980s, has pushed art to confront its limits once again. Julia Kristeva's essay on abjection draws attention to the relationship between object and subject that essentially characterises disgust (Kristeva 1982, 11-12).

The reaction of disgust, unlike other negative emotions such as shame, is mostly directed outwards and indicates the impossibility of assimilating, of making one's own, that is, an absolute otherness. The abject is therefore that which, struck by disgust, is to be rejected, to the point that it cannot be assimilated, not even through language or imagination: it is the unnameable and unrepresentable. Abject is not, however, identical with disgust. In both cases it is something that the nauseated subject rejects, perceiving the presence of the object as a threat. In both cases we are dealing 
with something repressed, that is, with the most animal dimension of our existence that has been made taboo. And in both cases, as Freud showed, the rejection that is expressed is traversed by a certain form of ambiguity, where the search for that which generates aversion becomes a manifestation of perversion (Freud 1999, $1930,144)$. Abjection and disgust are, however, essentially different, since the abject can find redemption, which is denied to disgust. This difference is still primarily due to the fact that the abject designates an object, whereas disgust always indicates the state of mind of a subject (Kristeva 1982, 11). Abjection elaborates "a trivium of phobia, obsession and perversion" which gives rise to a "perverse jouissance". It is a sublimation of abjection in the form of reconciliation with all that has been rejected. And this reconciliation is made possible, according to Kristeva, precisely through art (Kristeva 1982, 15-17).

The symbolic capacity of art is indeed capable of restoring the abject that has been rejected. Kristeva undoubtedly attributes a decisive role to the symbolic structures of art, which restore real being and truth. This conception of art, which is certainly not unique, is taken up by the artistic world, which is increasingly confronted with objects of waste, of rejection, that is, with the phenomena of abjection (Kristeva 1982, 5-7). This confrontation is not, however, a rehabilitation of disgust, nor does it go beyond the boundaries of aesthetics drawn at the time of its birth in the 18th century. The assimilation of the abject through art constitutes, in fact, a further step along the same path, inaugurated by Mendelssohn and Lessing, of legitimation of the ugly and then of the disgusting. In other words, it is still a question of "domestication".

The assimilation of the abject in art and literature evolved into the symbolic appropriation of reality that is today defined as Abject Art, Post-human Art or post-organic art: the body, particularly that of the artist himself, undergoes transformations, becoming itself the object of the work of art. Lea Vergine, in her book Body Art and Performace, states that "the artist becomes his object. Better, the artist is theetic of himself and is theetic of the object, that is, he places himself as the object, being aware of this process" (Vergine 1974). At the core of these artistic phenomena it is possible to glimpse a return to reality. This is however devoid of any filter, and offers a direct demonstration of reality itself to the senses of the observer. However, the concession of this truth is 
given by the abject art in an overbearing way, with a traumatic violence both for the spectator and for the artists themselves. It is a 'traumatic realism' that characterises the art of the abject season. Abject art thus reopens the same question that animated the mid-eighteenth-century debate on tragedy: what is it that attracts spectators to the numerous exhibitions of abject art? Why are audiences instinctively horrified and fascinated at the same time? It is not simply, or only, a search for continuous innovation, transgression and ever greater shocks, since this intention alone often leads to a habit of excesses that results in irony and indifference. Rather, it is necessary to resort to the symbolic nature of art, to its illusory character as opposed to the real, in order to understand these art forms as a tame and bearable restitution of the abject. It is then a purification of the impure. Typically, disgust affects that which is impure, the waste material that threatens the purity of the individual. The symbolic power of art can therefore assume a cathartic value in resolving the impure in the domestication achieved by artistic experience. Art, as catharsis par excellence, achieves a mediation that allows a mimetic identification with that which provokes disgust and annoyance, and only in this way is it possible to regress and incarnate the object, which is thus elevated once again. The excesses of excremental substances or pieces of organisms, even human ones, which have been present in museums and art galleries all over the world since the 1980s are evidence of this purification process (Clair 2004, 65-67).

\section{Art as domestication}

If, with Freud, one wants to understand art as the highest representation of that process of domestication of drives and instincts, in synthesis of the process of civilisation, one wonders how to read this paradoxical presence of what has a corporeal, instinctual and what drives in the product of the highest form of civilisation, education and culture, that is, in the work of art (Freud 1999, 1930, 12).

Exemplary of abjection, understood according to Kristeva's theory, is the corpse (Kristeva 1982, 108-112). The lifeless, or even decomposing, body is an expression of human duplicity and becomes a symbol of the fundamental contamination to which life, as humans, exposes us. In the history of religions, the corpse is that which must be excluded from all that is life and must not be allowed to contaminate the divine earth. The dead and decaying 
body stands for all that is not spiritual, symbolic and divine law (Kristeva 1982, 110-112). This dimension of disgust can be found in certain works by Damien Hirst, who in 1993 exhibited his shark in formaldehyde, freezing the moment in which a living body, full of spirit, becomes an abject element, a waste, a non-object (see Buelli 2017). And the mechanisms of abjection can also be seen at work in the success of Gunther von Hagens' exhibition, with its display of human corpses.

The theory of disgust allows us to read these phenomena of contemporary art, which confronts the corrupt and the disgusting, and which exhibit the impure in all its forms, as manifestations of the need for spirituality and purification. The more a body is pierced, destroyed, degraded and lifeless, the more it celebrates the living and eternal spirit. This theory ultimately confirms the strength of the taboo that governs art.

However, the contemporary art world is often in danger of forgetting the complexity still involved in excluding disgust from the artistic experience and including the disgusting and the abject in the art product. Jean Clair has recently drawn attention to what the relationship between art and disgust can mean for our civilisation. Combining the categories of classical aesthetics with Freudian theory, which sees disgust as the highest manifestation of our civilisation process, Clair denounces the situation in today's art world where museums are no longer instruments of culture, but are primarily subject to market and speculation (Clair 2004, 68). As Freud remarks, ambiguity characterises disgust as early as Plato's Parmenides. In Plato's text, 'hair, mud, dirt, or anything else devoid of importance and value' are defined as substances that exist only in appearance, that do not participate in any idea (Parm 130 A/D). In the Republic, these same substances that arouse horror also move desire. It is the ambiguity between horror and desire that drives a man to look obsessively at a gruesome scene, even though he knows it is gruesome. It is the ambiguity of feelings that grips Leontius in front of the abjection of the corpse: he could not look away from a pile of corpses outside the city walls, even though he was outraged by his own behaviour (Rep IV 439e440a).

According to Clair, the art of abjection "would be the state of an inferior art, or even an art of waste, an art of what remains after everything has been rejected". Clair rekindles the question of what qualifies the category of disgust as so interesting for aesthet- 
ics; and he also asks what makes this kind of art possible. "How is it possible that the public wants to admire Tracey Emin's dirty, unmade bed on display in one of the world's most important museums, or how can they stand the photographs taken furtively inside morgues by Andres Serrano or Jeffrey Silverthorne? More disturbing than their realisation is the reception given to such works. [...] The whole establishment of taste seems to applaud this art of abjection" (Clair 2004, 20).

The presence of the disgusting in art and the need to return to the body is clear in what is perhaps the most desecrating manifestation of 20th century art: the Viennese Actionism. The actions of Hermann Nitsch or Otto Mühl, apart from being extremely bloody, almost animalistic, feature religious symbols, bodily functions and sexual practices. They depart from the artistic tradition of using canvas or sculpture, the tempera is replaced by blood flowing from self-inflicted wounds, expression occurs freely, through one's own body. Although the places and times of the works are completely disrupted, they attempt to recreate ritual moments for therapeutic and cathartic purposes.

In this type of artistic creativity, which is directly confronted with the disgust, man becomes the very subject of sacrifice, but this individual is no longer a "bearer of culture", but an animalised human being, the zoological species 'human'. Abject art thus aims to concretise the ephemeral nature of life, to delimit time in the finiteness of the here and now. A reversal of artistic practices has accompanied the end of the use of classical figurative arts, renouncing the illusory power of art in favour of the use of the body in its naked and raw concreteness.

The ambivalence that characterises abject art also consolidates a further defining trait of disgust as an organ of distinction between the pure and the impure. Works of art that indulge in disgusting materials take on meaning solely because they are objects affected by disgust, and in this form of apparent violation of the barriers that constitute Western culture and civilisation, their existence is at the same time confirmed. Here, disgust is confirmed as a taboo of art. In artistic desecration, as a form of shattering the sacred, art expresses the need to overcome the taboo of disgust, but at the same time demonstrates its power. According to the definition of classical aesthetics, art is always an action of "composing"; art is a putting together; art is a putting into form. The human being is in fact unable to endure a decomposition of 
form, unable to represent a radical absence of form. In this respect, abject art does not constitute a unicum; instead, it represents the effort, common to all artistic expression, to give form to formlessness (Clair 2004, 61). Disgust continues to affect what cannot be assimilated and is a taboo that cannot be overcome. In this sense, the work of art remains, as Freud defined it, a mild form of hypnosis that allows us to reconcile with the outside world.

\section{Ethic of disgust}

Within this perspective aesthetic and moral disgust are to be seen as two different declinations of the same emotion. The most important difference between aesthetic and moral disgust lies in the notion of representation: the aesthetic representation shows its limits when art, even if it can certainly represent disgusting objects, is not able to trigger an authentic feeling of disgust as absolute displeasure (Feloj 2017, 69-82). Even if only a little portion of it, a kind of pleasure is always present in art. This is also the idea of Jean Clair who speaks about a domestication, that is a nullification, of disgust in art (Clair 2004, 71). On the contrary, moral disgust, that is, repugnance for bad behaviours, can be represented in art, through the subject of the representation, or also, sometimes, through the very performance of the artist. In this sense, art can also play a role in moral education by stimulating an emotional reaction to bad actions. Disgust can therefore become a moral instrument acting as a sort of negative motive. Disgust can also be defined, in Aurel Kolnai's words, as an ethical-cognitive emotion. I assume therefore that an important distinction needs to be assumed between the aesthetic representation that has its limit in disgust, and the moral representation that finds in it a useful instrument (Kolnai 2004, see Tedeschini 2018).

I also assumes that the aesthetic experience of art can have a moral meaning and also a moral function. In this regard, art can play a role in the process of education and of civilisation without having an explicit normative content. Based on this kind of assumption, disgust turns out to be a unique emotion: on the one hand, the emotion of disgust has a physiological essence, totally sensible, and it has developed as an instrument of defence against a possible body contamination; on the other hand, the emotion of disgust has a cultural essence, it requires development that can be 
accomplished through education, and it marks the progress of the civilisation process away from the animal state.

While taking into account the ethical nature of disgust, I make three main assumptions: 1 . The emotion of disgust is only apparently natural; it is instead deeply cultural and can be educated; 2 . As the emotion of disgust lies at the ground of our civilization process, it is not possible to totally overcome it; 3 . aesthetic and moral disgust need to be kept distinct, as the representation of disgusting objects in art is a domestication of the emotion of disgust, whereas moral disgust is part of our moral judging. These assumptions engage with Martha Nussbaum's work. The first monograph that Nussbaum dedicates to the emotion of disgust is published in 2004, Hiding from Humanity: Disgust, Shame, and the Law, the same year in which Jean Clair's essay appeared. In 2010 she writes another book on disgust that is actually an extension to her theory, From Disgust to Humanity: Sexual Orientation and Constitutional Law. Nussbaum supports a theory of disgust that is in some respects at variance with what this project supports: she states the need to overcome disgust as emotion antithetic to the emotion of respect and to a politics of humanity. Consistently with her objective, she focuses on the historical effects produced by a politics of disgust: exclusion and disdain of otherness and minorities on the ground of a rooted conservatism. Nussbaum's discussion of the emotion of disgust is clearly in line with her emotionalist ethics, her view of morals in which imagination and rational emotions have a fundamental function. In this perspective, the emotion of disgust is defined as an irrational emotion, that causes and has caused more damages than benefits in the application of the law; the emotion of disgust belongs therefore to those emotions which cannot and should not have an impact on the law (Nussbaum 2010, 26).

Martha Nussbaum takes the relay from the Handbook of Emotions (Rozin P., Haidt J., McCauley C.R. 2008) and from Paul Rozin's definition of disgust as a reaction to a contamination danger. This definition does not include any distinction between physical and moral disgust. It is however hard to avoid the evidence that disgust triggered by physical objects is qualitatively different from disgust triggered by moral actions. The art experience is a good test ground this distinction. If we assume that art always realizes only a domestication of disgust, it cannot educate to physical disgust, it can only show us, in vitro, what we have re- 
fused as disgust and removed as taboo. However works of art can often provide examples of a how the representation of what morally disgusts us not only develops our moral disgust but also educates us. By moral disgust I mean here the disgust we may feel when confronted with actions that we find morally reprehensible and unacceptable. We can find many examples of this in tragedy. In the case of physical disgust the object remains unnameable, unassimilable, unrepresentable; in the case of moral disgust, the moral action and the moral vice can find a representation and be the object of our direct disgust. This depends on the cultural essence of disgust and the need to be educated to the emotion of disgust (Feloj 2017, 157-61).

In Hiding from Humanity, Nussbaum distinguishes disgust from rage and indignation, and likens it to shame. Nussbaum also argues that seeing disgust as emotion that protects society from vice results in a highly implausible position. Shame and disgust are for Nussbaum totally different emotions compared to rage and fear, since they are particularly subjected to normative distortion and therefore unsuitable to inspire the law. According to Nussbaum, the emotion of disgust is problematic as it recalls the idea of contamination, it is a reaction against what is corrupted and, ultimately, also against what is corporal. In this sense, the emotion of disgust has been used to provide the ground to discriminatory practices by the dominant social group. The emotion of disgust, as reaction against what is corporal, perishable and also animal, is for Nussbaum the expression of our useless and irrational ambition to be a non-animal, immortal and ultimately non-human creature. On the contrary, the ideal of society to be promoted by the law is a society that acknowledges its own humanity, with its fragilities and vulnerabilities. Nussbaum finally admits that even if disgust is clearly the result of our education, it belongs to every society and it seems impossible to have a society without disgust (Nussbaum 2004). In her more recent book, From disgust to humanity, she deals more directly with a theoretical definition of disgust that includes also a moral declination of it. The main claim is always the same: the emotion of disgust is opposed to the emotions of respect and sympathy (Nussbaum, 2010, p. XV). In addition, she claims that "disgust relies on moral obtuseness" (Nussbaum 2010, p. XVII). This does not prevent her from stating that the emotion of disgust is a very powerful instrument, "a determi- 
nant of both social norms and lawmaking" (Nussbaum 2010, p. XX), "an especially visceral emotion" (Nussbaum 2010, 13).

The empirical studies on disgust by Paul Rozin and his research group are still the starting point. In recent years, Rozin has demonstrated that the emotion of disgust has a markedly cognitive feature and what is for us disgusting depends crucially from the idea that people have about a certain object. Again, what seems to strike a chord in Nussbaum is the fear of contamination that according to Rozin is the main cause of disgust (Rozin 2000).

Contrary to the evolutionist theories on disgust, Nussbaum does not see in the emotion of disgust a defence instrument, but rather an aversion against what is human, corporal and mortal. However, in From disgust to humanity, a new possibility is outlined, as Nussbaum writes: "such aversions almost certainly have an evolutionary basis, but they still have to be confirmed by learning: children do not exhibit disgust until the ages of two to three years old [...] this means that society has room to interpret and shape the emotion, directing it to some objects rather than others, as with anger and compassion" (Nussbaum 2010, 15). Based on this possibility, Nussbaum elaborates a notion of disgust that could be compared to the definition of moral disgust presented in this project; she calls it a "projective disgust" and she admits the possibility that the emotion of disgust can be shaped by society as essentially cultural. This openness is however not explored.

This possibility is nevertheless real, and art, as giving shape to the shapeless, can be one of the most powerful instrument that our society has to give shape to disgust and to educate it. Martha Nussbaum's theory of disgust, despite being hostile to this emotion, cannot avoid then to admit that it is not possible to overcome disgust and to eliminate it from our society. On the contrary, we can orientate it through culture. What is at stake here is an education to disgust: as also Jean Clair writes, we have to re-start learning disgust. A learning that can be (or should be) based on the moral law. What Nussbaum deprecates about the emotion of disgust as a discriminatory emotion in conservative politics is not to be referred to the disgust in itself, as a powerful instrument of morality, but to the ground in which it is cultivated. The solution to a distorted use of the emotion of disgust is not a complete overcoming of it (which is impossible), but rather an orientation towards other objects, as for example racist behaviour. In this direction goes the proposal presented by Jonathan Haidt, Clark 
McCauley, Daniel M.T. Fessler, and Simone Schnall. They interpret the emotion of disgust as a "normative neutral" emotion, that is as not determined by an infraction of a specific norm, even though it can be a powerful emotive instrument to recognize a norm violation. In this sense, losing the ability of feeling disgust means to be morally underprivileged (Clark, Fessler 2014, 486). Nussbaum's condemnation of disgust as an instrument for exclusion and conservative practices does not take into account that disgust can be applied to a lot of different phenomena and that, as an instrument, is empty, that is, without a pre-determined content (Clark, Fessler $2014,491)$. The emotion of disgust is therefore more sophisticated and flexible than it is generally agreed and the radical refusal that characterizes it is liable of adaptation to different circumstances, without being connected to a specific series of norms. For Clark and Fessler, the emotion of disgust marks the normative boundaries of our social and moral identity, excluding what violates our moral norms, without determining them (Clark, Fessler, 2015 , 495). A condemnation of disgust risks to be not only unjustified but also adverse to the promotion of morals. This is possible of course if we understand the moral disgust as a specific disgust. This doesn't mean however that the moral disgust has nothing to do with the physiological disgust. On the contrary, moral disgust maintains a link to its physical essence and on this ground, presents an interesting embodied cognitive function that grants a simple and quick intuition of what is morally wrong. Based on the notion developed by Johnson and Lakoff (1999), I read in conclusion the emotion of disgust as embodied schemata, that is, as an imaginative structure or an experiential model that yields a corporal or sensible knowledge (Haidt, Rozin et al. 1997, 123). The emotion of moral disgust turns out to be a sort of non-normative emotion, that is, an empty powerful instrument. In this reading the aesthetic experience of the work of art has a key function in the education of our emotion of disgust, certainly not normatively indicating what is morally wrong or right, but exercising our sensible rejection of what is morally unassimilable.

\section{Bibliography}

Buelli M., 2017 : Un'estetica del disgusto. Damien Hirst, Pomezia, Galassia Arte, 2017. 
Clair J., 2004 : De Immundo, Paris, Édition Galilée, 2004.

Clark J.A., Fessler D.M.T., 2015: “The Role of Disgust in Norms, and of Norms in Disgust Research: Why Liberals Shouldn't be Morally Disgusted by Moral Disgust", in Topoi, 34, pp. 483-498.

Douglas M., 1969: Purity and Danger, London and Henley, Routledge and Kegan Paul, 1969.

Feloj S., 2017: Estetica del disgusto. Mendelssohn, Kant e i limiti della rappresentazione, Roma, Carocci, 2017.

Freud S., 1999, 1930: Das Unbehagen in der Kultur, in Gesammelte Werke, Bd. 14, Frankfurt am Main, Fischer, 1966-1969; trans. by J. Strachey, Civilization and its Discontents, The Standard Edition of the Complete Psychological Works of Sigmund Freud (1927-1931), vol. XXI, Hogarth Press, London 1999, 57-146.

Haidt J., Rozin P., McCauley C.R., Imada S., 1997: "Body, Psyche, and Culture: The Relationship between Disgust and Morality", in Psychology and Developing Societies, 9.1, pp. 108-131.

Lakoff G., Johnson M., 1999: Philosophy in the Flesh: The Embodied Mind and Its Challenge to Western Thought, Chicago, University of Chicago Press, 1999.

Kolnai A., 2003: „Der Ekel“, in Jahrbuch für Philosophie und phänomenologische Forschung, ed. Edmund Husserl, Max Niemeyer, Halle/ Saale, 1929, vol. 10, pp. 515-569 (reprint 1974); trans. by B. Smith, C. Korsmeyer, On Disgust, Portland, Open Court, 2003.

Korsmeyer C., 2011: Savoring Disgust. The Foul and the Fair in Aesthetics, Oxford, Oxford University Press, 2011.

Kristeva J., 1982: Powers of Horror. An Essay on Abjection, trans. Leon S. Roudiez, New York, Columbia University Press, 1982.

Lessing G.E., 1990, 1766: Laokoon: Oder über die Grenzen der Malerei und Poesie (1766), in Werke 1766-1769, hg. von W. Barner, Bd. 5/2, Frankfurt am Main, Deutscher Klassiker Verlag, 1990.

Mendelssohn M., 1972, 1771: Philosophische Schriften (1771), in Gesammelte Schriften. Jubiläumsausgabe, hrsg. v. A. Altmann, M. 
Brocke, E.J. Engel, D. Krochmalnik, Stuttgart, FrommannHolzboog, 1972ss..

Menninghaus W., 2003: Ekel. Theorie und Geschichte einer starken Empfindung, Frankfurt a.M., Suhrkamp, 1999; trans. by H. Eiland, J. Golb, Disgust. Theory and History of a Strong Sensation, New York, SUNY, 2003.

Menninghaus, W., Wagner, V., Wassiliwizky, E., Schindler, I., Hanich, J., Jacobsen, T., \& Koelsch, S., 2019: „What are aesthetic emotions?", in Psychological Review, 126 (2), 171-195.

Miller W.I., 1997: The Anatomy of Disgust, Cambridge/ London, Harvard University Press, 1997.

Nussbaum M., 2004: Hiding from humanity: disgust, shame, and the law, Oxford, Princeton University Press, 2004.

Nussbaum M., 2010: From disgust to humanity: sexual orientation and constitutional law, Oxford, Oxford University Press, 2010.

Plato, Parmenides.

Plato, Republic.

Rozin P., Haidt J., McCauley C.R., 2008: Disgust, in Lewis M., Haviland-Jones J.M., Feldman Barrett L., Handbook of Emotions, New York-London, The Guildford Press, 2008, 757-776.

Rozin P., 2008: "Hedonic "adaptation": Specific habituation to disgust/death elicitors as a result of dissecting a cadaver", in Judgment and Decision Making, 3.2, pp. 191-4.

Tedeschini M., 2018: Il conflitto estetico. Teoria del disgusto, Lithos, Roma 2018.

Vergine L., 1974: Body Art e storie simili. Il corpo come il linguaggio, Milano, Skira, 1974. 